\title{
The Effect of Incubator Type on Hatchability and Chick Survival of Emu Dromaius Novae Hollandiae (Le Souef 1907)
}

\author{
${ }^{1}$ ADEWUMI, A.A; AYODELE, I.A.; LAMEED, G.A \\ ${ }^{I}$ Department of Animal Science and Fisheries Management, Bowen University, IwoE-mail: abibay2001@yahoo.com \\ ${ }^{2}$ Department of Wildife and Fisheries Management, University of Ibadan, Ibadan \\ ${ }^{3}$ Department of Wildlife and Fisheries Management, University of Ibadan, Ibadan.
}

\begin{abstract}
The population of wildlife is declining due to unsustainable harvest for meat. There is need to increase animal protein to fill the gap between the demand and supply from conventional sources through production and management of non-conventional sources of meat like Emu Dromaius novaehollandiae. In this study hatchability and chick survival due to the use of two different types of incubators examined. Sixteen birds aged 20 month were managed in eight pens $(25 \mathrm{~m}$ by $25 \mathrm{~m}$ each) under semi intensive system at Ajanla farms, Ibadan at the rate of one male to one female per pen. They were fed with pelleted feed and Tridax procumbens. Eggs were collected daily for viability test before setting and hatching in two different types of incubators; electric cabinet and kerosene incubators. Both were maintained at a temperature of $40^{\circ} \mathrm{C}$ and $25 \%$ relative humidity. Hatched chicks were monitored for the first six weeks of life to determine chick survival. Data obtained were analyzed using ANOVA. Proximate analysis of the diet revealed that it contained $45 \%$ crude protein. Average production for three years was $62+2.4$ eggs, with a total average of $35+18.2$ eggs per hen during the breeding period. The mean weight recorded for Emu eggs was $625+2.59 \mathrm{~g}$. Fertility percentage was $75.4 \%$. Average hatchability of $60.4 \%, 70.1 \%$ and $65.4 \%$ observed for kerosene-operated incubator for 2002, 2003 and 2004 respectively were significantly higher $(\mathrm{P}<0.01)$ than $17.5 \%, 16.1 \%$ and $18.2 \%$ respectively for the electric incubators. For both incubators, incubation period was 50 days. The average weight of newly hatched chick was 414g. Mean weight of hatchings from kerosene and electric incubators were $418.5 \mathrm{~g} ; 409,6 \mathrm{~g}$ respectively. Mortality recorded in hatchlings from electric incubator was $30 \%$ while that for kerosene incubator was $10 \%$. There was low hatchability in electric incubator compared to kerosene incubator. @ JASEM
\end{abstract}

Wildlife is a natural resource that represents the principal source of animal protein for the rural majority in most African countries (Ajayi 1979, Ayeni et al, 1982). The supply of bush meat from wildlife stands out to bridge the gap between livestock production and human population growth. Ajayi (1971) reported that in developing countries livestock production is increasing at a rate of 1.25 $2.0 \%$ per annum while protein demand is expected to grow at $5 \%$ per annum over the period to 1985 . Hatchability depends on good incubation condition, all other things being equal. Artificial incubation of emu eggs needs to aim at creating condition such as incubation humidity and temperatures to stimulate the natural condition. The average hatchery sequence for the chick to break into air cell is at 47 day of incubation while to pip the eggshell is at 49 day and to complete hatching at 50 day. However, the time interval is subject to normal biological variations. Hatchability problem could be due to heavier egg and hyperthalmia,that is, when the egg temperature is higher than ambient temperature by $2{ }^{\circ} \mathrm{C}$ towards the end of incubation. Incubation problems can be categorized into infertility of eggs, early embryonic death [up to fourteen days of incubation] and late term embryonic death [29-50 day of incubation] and dead in shell [at time of hatching].

\section{MATERIALS AND METHOD}

Sixteen (16) adult emu, twenty months old each at the ratio of one male to one female were managed, at Ajanla farm for the study. The birds were weighed before the start of the experiment. The average weight of the birds in each pen was $68+$
$1.12 \mathrm{~kg}$. Any bird with the following physical disability was excluded from stocking:

Curvature of the spine or neck, Eye infections, dull feathers, emaciation and other signs of illness, Excessively wild birds (prone to injury). Blood in stool, which indicates problems. Extremely dome shapely back and obesity. Pairs of Emu (one male to one female) were housed in eight pens. A horsewire was used to fence each pen. The height of the pens was $1.8 \mathrm{~m}$ tall supported with a top rail for greater strength. All the fasteners were turned outwards so as to avoid scrape or injury of birds' neck.

Eggs were collected in the morning during feeding time in order to cause the least amount of stress. As the breeding season continued, males were found sitting on the fresh eggs. The eggs were collected at night by moving quietly without flash light around the birds. Males were gently lifted by grasping one of the legs tucked under them, and the eggs removed. Usually the male was already in a state of trance - like incubation state and did not offer any resistance when being lifted and put down again. Eggs were collected into a clean container that had been cushioned with clean hay to ensure eggs do not roll. Eggs were marked (numbered and dated) with a white coloured pencil. This method was useful in identifying the eggs laid from the eight different pens used for the study. All eggs laid and collected were not treated with any chemical or washed. Dirts were removed from eggs by using a small dry brush prior to incubation. Eggs were also checked for morphology and the abnormally shaped eggs are removed from the collection before incubation. Soft-shell, cracked / 
pecked eggs were also removed from the collection. The emu eggs were artificially incubated in two different types of incubators. Electric cabinet incubator and Kerosine incubator at a regulated temperature of $40^{\circ} \mathrm{C}$ and relative humidity of $25 \%$ for fifty days. The eggs were weighed; the long and short axes were measured with a caliper to calculate the shape index. Eggs, which have been damaged during transport, were used for chemical assays. The study looks into egg hatchability based on the feeding ration and in two different type of incubators. During incubation eggs were candled with a Powertee Model RPS 1204 on day 7, 14, 28 and 49. The timing of hatching was monitored; if it exceeded 24 hours, the chicks were assisted in leaving the shells. The newly hatched chicks were weighed to determine the chick percent contribution to the egg weight. On termination of hatching, the unfertilized eggs and those containing dead and unhatched embryos were opened. Hatchability indices were calculated for each egg batch. Once hatched the chicks were kept in the Hatcher for 24 hours and then transferred to a nursery pen for the first 3 days after hatch. The chicks were kept at $30^{\circ} \mathrm{C}$ under a "mock hen", the surrounding temperature being $26^{0}$ C. At the end of first week the temperature was decreased to $28^{0} \mathrm{C}$ and $24^{0} \mathrm{C}$ relatively; the temperature was further decreased by $2^{0} \mathrm{C}$ every subsequent week, down to $20-22^{0} \mathrm{C}$. The hatched chicks were fed full pelleted mixed feeds containing $45 \%$ protein, $2685 \mathrm{kcal} / \mathrm{kg}$ and $4 \%$ dietary fibre. Until the sixth week of life the chicks were weighed at weekly intervals to determine their growth rate the following formulae was used;

$$
\begin{aligned}
& \text { gr }=(\mathrm{We}-\mathrm{Wb}) / 0.5(\mathrm{~Wb}+\mathrm{We}) \text {, where; } \\
& \mathrm{gr}=\text { growth over a given period } \\
& \mathrm{Wb}=\text { body weight at the beginning of the period } \\
& \mathrm{We}=\text { body weight at the end of the period. }
\end{aligned}
$$

The hatched chicks were examined throughout the period of study; deaths and health defects were recorded, the dead birds were autopsied. Inference was drawn based on the different treatments and the type of incubation method.

\section{RESULTS AND DISCUSSION}

Dietary treatment does not have any influence on the egg weight, shape and size during the study as shown in table 9 there is no significant differences between the eggs collected from different dietary treatment.

Table 1: The egg weight and shape indices

\begin{tabular}{llllll}
\hline Parameter & & \multicolumn{3}{c}{ DIETARY } & \multicolumn{2}{c}{ TREATMENT of Stern (1991) that optimally, the ratite eggs } \\
\cline { 2 - 6 } Egg Weight $(\mathrm{g})$ & $\mathrm{X}$ & 625.50 & 625.00 & 627.74 & 629.48 \\
& $\mathrm{SD}$ & 56.50 & 56.10 & 62.10 & 55.04 \\
& $\mathrm{X}$ & 66.37 & 66.10 & 65.81 & 66.03 \\
& $\mathrm{SD}$ & 3.08 & 2.98 & 3.22 & 2.81 \\
\hline Shape Index & &
\end{tabular}

\begin{tabular}{|c|c|c|c|c|c|c|c|}
\hline \multirow[t]{2}{*}{ Group } & \multicolumn{2}{|c|}{$\begin{array}{l}\text { Weight before } \\
\text { Incubation }\end{array}$} & \multicolumn{2}{|c|}{$\begin{array}{l}\text { Weight on day } \\
49 \text { of Incubation }\end{array}$} & \multicolumn{2}{|c|}{$\begin{array}{l}\text { Weight } \\
\text { loss }\end{array}$} & \multirow[b]{2}{*}{$\%$} \\
\hline & $X$ & SD & $\mathrm{X}$ & SD & $\mathrm{X}$ & SD & \\
\hline DT 1 & 627.21 & 75.20 & 554.58 & 52.00 & 72.63 & 8.35 & 11.50 \\
\hline DT 2 & 630.35 & 75.62 & 556.96 & 62.35 & 73.04 & 12.21 & 11.59 \\
\hline DT 3 & 623.82 & 75.70 & 550.96 & 64.0 & 72.86 & 10.20 & 11.68 \\
\hline DT 4 & 628.10 & 75.30 & 555.20 & 53.20 & 72.90 & 8.21 & 11.61 \\
\hline
\end{tabular}

* Corresponding author: Adewumi, A.A.

Table 2: Egg weight loss during incubaton (g. \%) for the 4 - dietary treatments (dt)

\section{EGG WEIGHT LOSS}

Chick quality depends on the egg water loss, Weight losses during 49 days in the incubator were similar in all dietary treatments, and for the two types of incubators used for the study. No significant differences were observed between them. Minnar and Minnar (1993) were of the opinion that if the water loss over a 49 -days long incubation is not lower than $10 \%$ and not higher than $20 \%$ it can be regarded as appropriate,

Table 2: showed that the effect of diet did not have any significant difference on egg weight loss during incubation. Percentage weight loss for D-1, D-2, D-3 and D-4 were 11.50, 11.59, 11.68 and 11.61 respectively.

\begin{tabular}{|c|c|c|}
\hline Item & Group (Inc & ubator type) \\
\hline & Electric (\%) X & Kerosine (\%) X \\
\hline $\begin{array}{l}\text { Hatchability of } \\
\text { Set eggs }\end{array}$ & X $17.3 \pm 1.2$ & X $65.3 \pm 5.1$ \\
\hline Incubation (days) & 50 & 50 \\
\hline $\begin{array}{l}\text { There was a si } \\
\text { hatchability.( } \mathrm{P} \\
\text { hatchling than E } \\
\text { respectively. }\end{array}$ & $\begin{array}{l}\text { ignificant effect } \\
<0.05 \text { ) .Kerose } \\
\text { Electric incubato }\end{array}$ & $\begin{array}{l}\text { of incubator } \\
\text { ne incubator pr } \\
\text { r. } \quad 65.3 \pm 5.1 \% \text { t }\end{array}$ \\
\hline
\end{tabular}

\section{HATCHABILITY DUE TO INCUBATOR TYPE:}

Table 3: Hatchability in relation to type of incubator

TABLE 4: Relationship between Chick and Egg Weight in the two different types of Incubators used for the study. Incubator Egg weight (g) Chick weight (g) Chick weight

\begin{tabular}{llcllcc} 
& & & \multicolumn{4}{r}{ As \% of Egg Weight } \\
\hline $\begin{array}{l}\text { Electric } \\
\text { Cabinet }\end{array}$ & 625.50 & 56.50 & 414.01 & 61.72 & 66.20 & 3.15 \\
\hline Kerosene & 625.0 & 56.10 & 412.85 & 60.00 & 66.06 & 3.01
\end{tabular}

Differences not significant $(\mathrm{P}<0.05)$

Keeping with the design of the study egg hatchability was related to types of incubator due to turning rate however turning rate significantly outwits results of incubation (Table 4 ) The highest percentage of dead embryos in this study was recorded in electric cabinet incubator and the highest hatchability rate in fertilized eggs was recorded in kerosene-operated incubator. However all the fertilized eggs incubated were not stored more than one - week according to the suggestion NT of Stern (1991) that optimally, the ratite eggs 4 should not be stored before incubation for a period .04 longer than one week. 


\section{CONCLUSION}

The success of emu farming depends on good hatchery management. The use of artificial incubation in this study revealed that kerosene operated incubator was better than electric cabinet incubator. This could be due to the differences in the turning rate. While turning rate was done six times in a day for kerosene operated incubator the electric cabinet incubator has been programmed to turn for 4 times in a day.

\section{REFERENCES}

Adewumi, A A (2006) Effect of feed type on fecundity and hatchability of emu Dromaius novaehollandia (Le Souef, 1907) under captivity and subsequence performance. $\mathrm{PhD}$ Thesis University of Ibadan, Nigeria.
Ajayi, S. S. (1971) Wildlife as a source of protein in Nigeria: Some priorities for development. Wildlife Bulletin of Nigeria. No 2,1974. Are port from the "Nigerian field" Vol. xxxvi, No 3, July 1971.pp 115-127.

Ajayi, S. S. (1979), Utilisation of Forest Wildlife in West Africa.FO/MISC.79/26 Dec. 1979. F.A.O. Rome.

Ayeni, J S O;. Afolayan, T A ; Ajayi, S. S. (1982) Introductory Handbook on Nigerian Wildlife SAOLOG. Printing production, Ilorin, Kwara state, $198280 \mathrm{pp}$

Minnar P; Minnar, M (1993), The Emu Farmer's Handbook. Induna Company Groveton., Texas

Stern, C D (1991), The sub-embryonic fluid of the domestic fowl and its relationship to the early development of the embryo. Avian incubation, London: 81-90. 